\title{
Analysis of adoption trends of in-parlor technologies over a 10-year period for labor saving and data capture on pasture-based dairy farms
}

\author{
W. Yang, ${ }^{1} \oplus$ J. P. Edwards, ${ }^{2} \odot$ C. R. Eastwood, ${ }^{2 *} \oplus$ B. T. Dela Rue, ${ }^{2} \odot$ and A. Renwick ${ }^{1} \odot$ \\ ${ }^{1}$ Department of Global Value Chains and Trade, Faculty of Agribusiness and Commerce, Lincoln University, Lincoln 7647, New Zealand \\ 2DairyNZ Ltd., PO Box 85066, Lincoln University, Lincoln 7647, New Zealand
}

\begin{abstract}
The use of precision technology is increasingly seen as an option to improve productivity, animal welfare, resource use efficiency, and workplace features on dairy farms. There is limited research related to longitudinal adoption patterns of precision dairy technologies and reasons for any patterns. The aim of this analysis was to investigate trends in technology adoption regarding both the amount (number of farms with a technology) and intensity (number of technologies per farm) of adoption. Surveys of parlor technology adoption were conducted on New Zealand dairy farms in 2008, 2013, and 2018 , with 532,500 , and 500 respondents, respectively. Technologies were grouped into labor-saving (LS, such as automatic cluster removers) or data-capture (DC, such as in-line milk meters) categories. Trends were examined for farms that had only LS, only DC, or LS+DC technologies. Technology adoption increased over time; the likelihood of technology adoption in 2018 (and 2013 in parentheses) increased by 21 (22), 7 (68), and $378 \%$ (165) for LS, DC, and LS+DC technology groups, respectively, compared to 2008. Farms with LS+DC technologies also had a greater proportion of LS technologies compared to non-LS+DC farms, although this relationship declined over the 10-yr period. The use of a rotary versus herringbone parlor was estimated to be associated with 356 and $470 \%$ increase in the likelihood of adopting LS technologies and LS+DC, respectively, from 2008 to 2018. Regional differences in adoption were also found, with the likelihood of adopting DC and LS+DC technologies found to be 46 and $59 \%$ greater, respectively, in the South Island of New Zealand, compared to the base region of Waikato. The results highlight the importance of understanding spatial and temporal farm characteristics when considering future effect and adoption of precision dairy
\end{abstract}

Received April 16, 2020.

Accepted August 19, 2020.

*Corresponding author: callum.eastwood@dairynz.co.nz technologies. For example, the analysis indicates the occurrence of 2 trajectories to technology investment on farms, where larger farms are able to take advantage of technology opportunities, but smaller farms may be constrained by factors such as lack of economies of scale, limited capital to invest, and inability to retrofit technology into aging parlor infrastructure.

Key words: dairy, technology, adoption, labor saving, data capture, investment

\section{INTRODUCTION}

The increase in average herd size in countries with pasture-based dairy industries, such as New Zealand (NZ) and Ireland, has created challenges for farmers related to attracting and retaining employees (Eastwood et al., 2020), along with the increasing complexity of managing larger herds (Gargiulo et al., 2018). Dairy farming has traditionally been characterized by long and unsociable work hours, making it challenging to attract new staff when competing against industries with conventional work hours (Deming et al., 2018). Average working weeks on dairy farms have been shown to exceed 50 h/wk in Ireland and NZ (Deming et al., 2019; Eastwood et al., 2020). Milking-related tasks alone account for 40 to $50 \%$ of the working hours on dairy farms in countries such as Ireland and NZ, which, combined with early start times (before $0500 \mathrm{~h}$ ) and long days (more than 12 h; Edwards et al., 2020), can negatively affect desirability of dairy farming careers (Eastwood et al., 2020). The challenge in sourcing employees requires changes in practices or technologies to reduce milking times and overall workloads, increase labor efficiency, make dairying easier for nonskilled entrants, and enhance the image of innovativeness (Eastwood et al., 2020). Technological innovation provides farmers with an opportunity to consider new approaches that improve farm management flexibility, adaptability, and productivity. However, employing technology to address these challenges requires a balancing act with costs of production and restrictions of debt levels, both major issues confronting many dairying nations cur- 
rently (Shadbolt et al., 2017; Kelly et al., 2020; van den Pol-van Dasselaar et al., 2020).

Greater use of precision technology on farm has been promoted as one approach to meet some of the challenges facing farmers, such as the need for resource use efficiency, access to skilled labor, and proof of practice for market access (Wolfert et al., 2017; Shepherd et al., 2018). There are 2 ways in which technology could be beneficial. First, labor-saving technology that automates a task (e.g., automated milking cluster removal that can reduce the people required at milking) can help farmers manage larger dairy herds by improving labor efficiency, reducing physical efforts, or allowing a decrease in work hours, making it more attractive for staff (Dela Rue et al., 2020). Second, data-capture technology that increases the amount of timely data available to the farmer can help with managing more complex systems and improve productivity and responsiveness to environmental and animal welfare issues (Barnes et al., 2019; Smith, 2020). However, despite these potential advantages, the rate of adoption of precision farming technologies remains low (Rutten et al., 2013; Borchers and Bewley, 2015; Gargiulo et al., 2018).

Previous research has identified potential reasons for the low uptake of precision dairy farming technologies. These include limited or unclear return on investment (Dolecheck et al., 2016; Thomas et al., 2019) potentially due to differences in herd size or dairy type and age, poor experiences due to a lack of support (Eastwood et al., 2012), or the rapid pace of technological advancement resulting in delayed investment decisions by farmers (Rutten et al., 2018). Several studies have examined dairy farming technology adoption at a point in time and found varying levels of adoption (Borchers and Bewley, 2015; Edwards et al., 2015; Gargiulo et al., 2018; Dela Rue et al., 2020). These studies have used either online or phone survey methods to assess technology adoption; however, by providing only one point in time, no adoption trends can be ascertained. Longitudinal data, such as presented in this current study, can provide insights into changes in technology uptake across different farming contexts such as size, infrastructure, and location.

Analysis of the data from surveys of parlor technologies has indicated a farmer preference for automation technologies aimed at labor-saving (Dela Rue et al., 2020). Additionally, research has indicated that automation represented an initial step for farmers investing in precision technologies (Eastwood et al., 2016). Initial analysis of data from technology surveys conducted every $5 \mathrm{yr}$ in NZ highlighted technology adoption trends but did not examine temporal and spatial interactions between variables (Edwards et al., 2015; Dela Rue et al., 2020). Studies of the adoption of technology in other contexts has highlighted a step-wise pattern (Byerlee and de Polanco, 1986; Higgins et al., 2017), where users get familiar with one technology before investing in a related technology. There is limited published evidence related to the longitudinal adoption patterns, and reasons for those patterns, of precision dairy technologies. The aim of the current study was to investigate trends in parlor technology adoption, regarding both the amount (number of farms with a technology) and intensity (number of technologies per farm) of adoption. We tested the hypothesis that over time there would be greater adoption of data-capture (DC) parlor technologies on farms that have also invested in laborsaving (LS) technologies, compared with farms that have no LS technologies. Our results provide guidance to technology research and development companies on the priority areas for investment and could be used to indicate likely trends for the adoption of precision technology.

\section{MATERIALS AND METHODS}

\section{Data and Descriptive Statistics}

The data used in this study were from 3 phone-based surveys regarding farmers' in-parlor technology investment decisions (Table 1). Findings from individual years in the data set have been summarized by Edwards et al. (2015) and Dela Rue et al. (2020), in this current paper we undertook a novel longitudinal trend analysis by combining the results from all 3 surveys. The surveys had a total of 532,500 , and 500 respondents in 2008, 2013, and 2018, respectively. In 2018, around $69 \%$ of NZ parlors were herringbones, $30 \%$ were rotaries, and $1 \%$ were other. Herringbone parlors are typically $50^{\circ}$ swing-over design (without rapid-exit or stanchion bailing), and rotaries are typically of external design. Technology adoption varies considerably within and between parlor types. For example, in 2018, 56\% of NZ herringbone dairies had no technology installed compared with $10 \%$ of rotaries. Further, for rotary parlors, $77 \%$ had automated cluster removers in 2018, but only $49 \%$ had automatic drafting (Dela Rue et al., 2020). In this study, rotary dairies were over-sampled to ensure a sufficient sample size to draw conclusions about both herringbone and rotary parlors separately. The technologies surveyed focused on animal sensors and milking-related technologies (technology installations that differ by parlor type). The survey questions related to 4 main aspects: physical farm details, the respondent's role in the business, their attitudes toward technology, and the technologies installed on farm. Each survey was conducted in the April to May period 
Table 1. Details from the 3 dairy technology phone surveys in 2008, 2013, and 2018, New Zealand

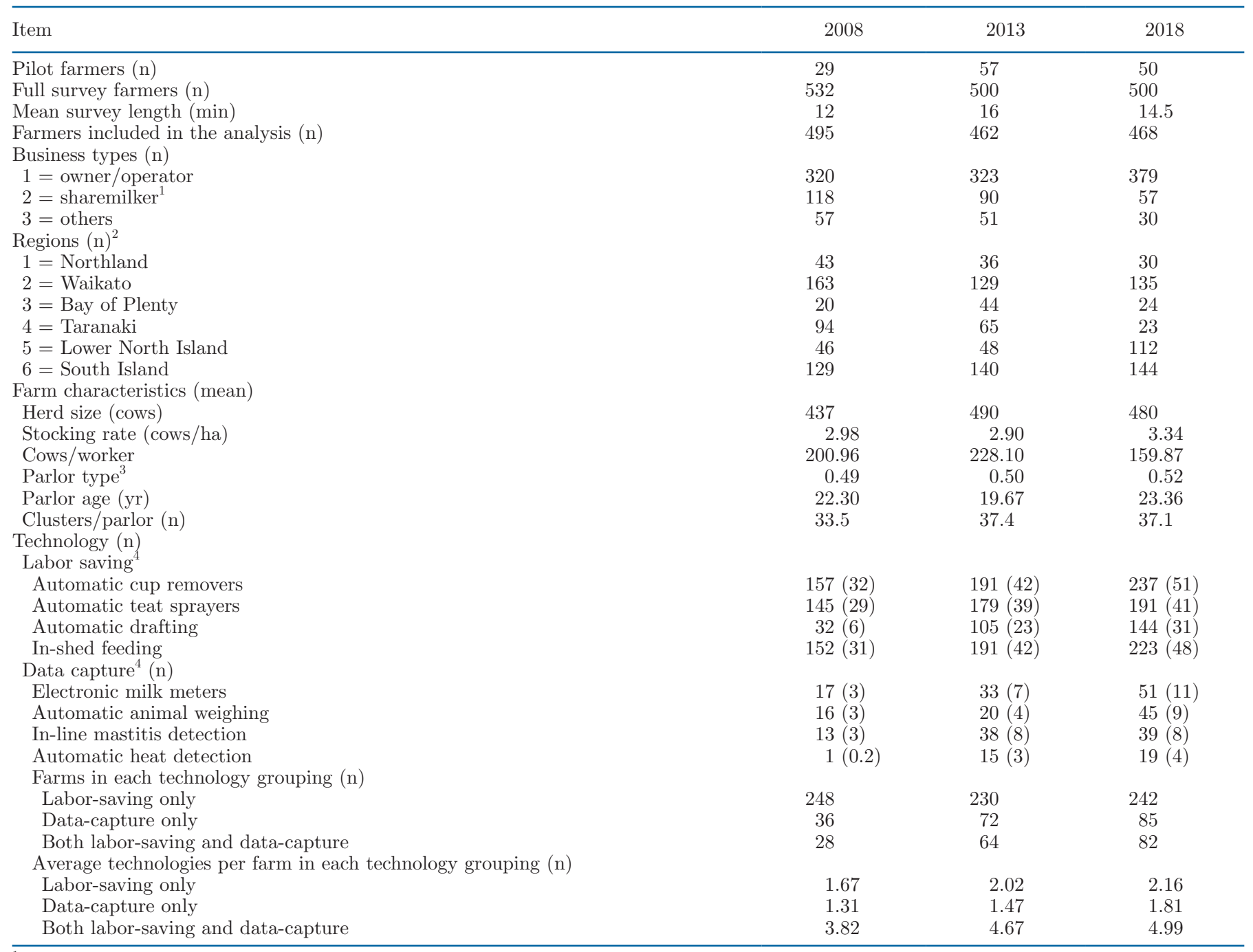

${ }^{1}$ Sharemilker refers to a person who works another's dairy farm for a share of the profits, sometimes owning all or part of the herd.

${ }^{2}$ The 2008 survey grouped the 3 South Island regions (West-Coast-Tasman, Marlborough-Canterbury, Otago-Southland) together, with 129 observations in total.

${ }^{3}$ The mean of parlor type represents the proportion of rotary in the sample (e.g., $49 \%$ rotary in 2008).

${ }^{4}$ The values reported in parentheses represent the percentage of farmers who adopted the technology.

by the same professional surveying company and included initial piloting with approximately 50 randomly selected dairy farmers. Surveys lasted approximately 15 min. Farmer contacts were randomly selected from a database containing details for approximately 11,000 dairy farmers ( $\sim 92 \%$ of all NZ dairy farmers) and were distributed proportionately across NZ. As the farmer contacts were randomly selected from the database for each survey, and farm identifiers were not collected to provide anonymity, the analysis in the current study does not represent the same 500 farms over time, rather a representative snapshot of the NZ dairy sector at each survey time point. In the phone surveys, interviewers asked to speak to the householder able to answer ques- tions relating to milking and the equipment installed in the parlor. Where participants were involved with more than one farming operation, they were asked to answer questions relating to the farm they were most familiar with.

To understand farmers' adoption decision making for LS and DC technologies (see Table 1), we created 2 types of outcome variables: (1) technology adoption, a categorical variable representing 4 adoption choices, where $0=$ not to adopt any technology, $1=$ only to adopt LS technologies, 2 = only to adopt DC technologies, and $3=$ to adopt both LS and DC technologies $(\mathbf{L S}+\mathbf{D C})$; and (2) intensity of technology adoption measured as a count variable of LS, DC, and LS+DC, 
defined as the number of technologies adopted out of the 4 possible technologies in each grouping, where the more technologies adopted, the greater the intensity of adoption. Detailed descriptions of variables in the regression models are shown in Table 2 , and further information about the types of LS and DC technologies is presented in Table 1. In addition, the potential factors (independent variables) that may affect farmers' investment decision making were included in Table 2, most of which are related to farm characteristics (e.g., herd size). To capture the timing effect of farmers' adoption of different technologies, we also included categorical variables Year, representing the year of the survey, to see if farmers' adoption, and intensity of adoption, of the technologies changed over time. Descriptive statistics of the variables by technology adoption (LS, DC, LS+DC, and nonadoption) are included in the Supplemental Table S1 (https://doi.org/10.3168/jds.2020-18726).

\section{Econometric Models}

Econometric models were used to address 2 main questions, including: (1) what factors affect the amount of farms with LS or DC technologies, and (2) what factors affect the average per farm intensity of technology adoption. Here, we assume that the ith farmer faces $J$ choices of adoption $(J=0,1,2,3)$, as described in outcome variable (1). Based on utility maximization, if farmer $i$ makes choice $j$ in particular, then we assume that $U_{i j}$ representing the utility associated with the choice $j$ is the maximum among the $J$ utilities, with $Y_{i}$ denoting the choice made. Thus, the statistical model is driven by the probability of choosing $j$ as $\operatorname{Prob}\left(U_{i j}\right.$ $\left.>U_{i k}\right)$ for all other $k \neq j$. Hence, we adopted a multinomial logit model, as shown in Equation 1 to explore the factors $X_{i}$ affecting farmers' choices of technology adoptions:

Table 2. Descriptions of the variables included in regression models for amount and intensity of technology adoption on New Zealand dairy farms

\begin{tabular}{|c|c|c|c|}
\hline \multirow[b]{2}{*}{ Variable } & \multirow[b]{2}{*}{ Description } & \multicolumn{2}{|c|}{ Descriptive statistic } \\
\hline & & Mean & $\mathrm{SD}$ \\
\hline Technology adoption & Categorical variable & & \\
\hline Labor-saving & Dummy, only adopt $(=1)$ labor-saving technologies or not $(=0)$ & 0.51 & 0.50 \\
\hline Data-capture & Dummy, only adopt data-capture technologies $(=1)$ or not $(=0)$ & 0.01 & 0.11 \\
\hline Both technologies & Dummy, adopt both labor-saving and data-capture technologies $(=1)$ or not $(=0)$ & 0.12 & 0.33 \\
\hline \multicolumn{4}{|c|}{ ( } \\
\hline Labor-saving & Counts of adopting labor-saving technologies & 1.36 & 1.62 \\
\hline Data-capture & Counts of adopting data-capture technologies & 0.22 & 0.63 \\
\hline Both technologies & Counts of adopting both technologies & 0.58 & 1.65 \\
\hline $\mathrm{X}$ & Independent variables (factors) & & \\
\hline Herd size (cows) & Continuous, the number of animals & 468.43 & 348.06 \\
\hline Stocking rate (cows/ha) & Continuous, herd size $\div$ farm size & 3.07 & 1.58 \\
\hline \multirow{3}{*}{ Business types } & Categorical variables: $1=$ owner/operator & 0.72 & 0.45 \\
\hline & $2=$ sharemilker $^{1}$ & 0.18 & 0.39 \\
\hline & 3 others $^{2}$ (set as base) & 0.10 & 0.28 \\
\hline \multirow[t]{6}{*}{ Region } & Categorical variables: 1 = Waikato (set as base) & 0.30 & 0.46 \\
\hline & $2=$ Northland & 0.08 & 0.27 \\
\hline & $3=$ Bay of Plenty & 0.06 & 0.24 \\
\hline & $4=$ Taranaki & 0.13 & 0.33 \\
\hline & $5=$ Lower North Island & 0.14 & 0.35 \\
\hline & $6=$ South Island & 0.29 & 0.27 \\
\hline \multirow[t]{3}{*}{ Year } & Categorical variables: $1=2008$ (set as base) & 0.35 & 0.48 \\
\hline & $2=2013$ & 0.32 & 0.47 \\
\hline & $3=2018$ & 0.33 & 0.47 \\
\hline
\end{tabular}

${ }^{1}$ Sharemilker refers to a person who works another's dairy farm for a share of the profits, sometimes owning all or part of the herd.

${ }^{2}$ Other types of businesses include managers, contractors, equity partners and other business. 


$$
\operatorname{Prob}\left(Y_{i}=j \mid X_{i}\right)=\frac{\exp \left(X_{i} \beta\right)}{\sum_{j-1}^{J} \exp \left(X_{i} \beta\right)} .
$$

The unknown parameters $\beta$ are used to estimate the relationships between the factors and farmers' choices through Equation 2, with a constant of $\alpha_{i}$ and $\varepsilon_{i}$ as the error term. This provides 3 sets of regression results, given we have 4 choices, and the baseline is set to be no adoption.

$$
\log \left[\frac{\operatorname{Prob}\left(Y_{i}=k\right)}{\operatorname{Prob}\left(Y_{i}=0\right)}\right]=\alpha_{i}+X_{i} \beta+\varepsilon_{i}, k=1,2,3 .
$$

Furthermore, we employed a Poisson regression model as the base model to estimate the determinants of the number of precision technologies per farm in the following equations, where $\gamma$ is associated with the independent variables to be estimated using Equation 3.

$$
\operatorname{Prob}\left(Y=y \mid X_{i}\right)=\frac{\exp \left(-\lambda_{i}\right) \lambda_{i}^{y_{i}}}{y_{i} !}, y_{i}=0,1,2, \ldots, \lambda_{i}=\exp \left(\alpha+X_{i}^{\prime} \gamma\right) .
$$

We used 3 Poisson regression models to explore the intensity of technology adoption, where the descriptions of the 3 models are shown in Table 3. The first model (Labor-saving intensity 1) includes the farmers who adopted only LS technologies $(\mathrm{n}=720)$. The second model (Labor-saving intensity 2) targeted the farmers who adopted only LS technologies, as well as those who adopted both LS and DC technologies $(\mathrm{n}=894)$. For these 2 models, the counts of LS technologies were included as the dependent variable. Notably, for the second model, a new independent variable (named Plus data-capture) was included to capture the association between adopting DC technologies and the intensity of adoption of LS technologies. This variable was also interacted with the year dummy 2013 and 2018 to cap-

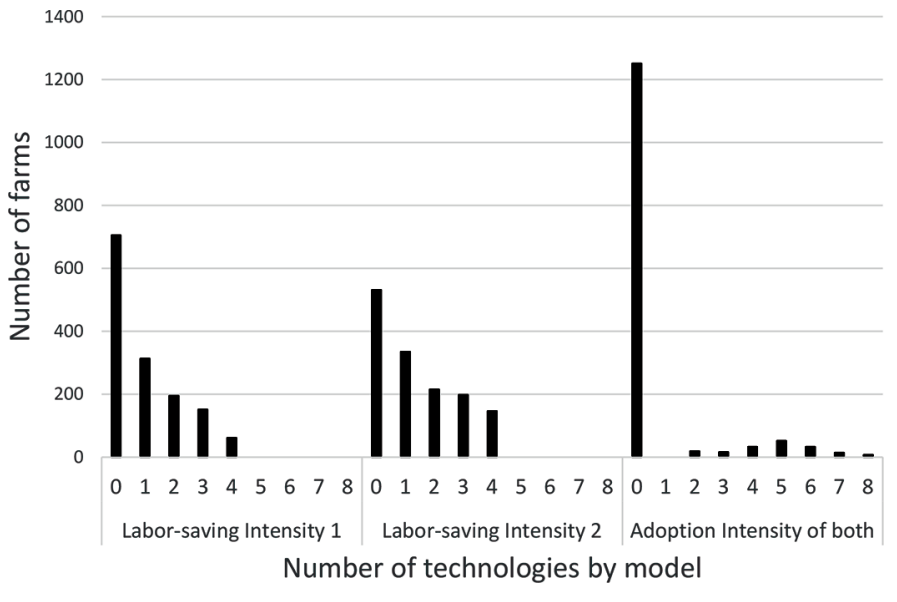

Figure 1. Visualization of the intensity of adoption for 3 parlor technology groupings on New Zealand dairy farms.

ture the change of the add-on effect over time. The final model (Adoption intensity of both) focuses on farmers who adopted both LS and DC technologies (n $=174$ ), and the counts of both technology adoptions were included as the dependent variable. Here, the estimated coefficients were exponentiated for all 3 Poisson regression models, representing the expected number of technologies adopted. Note that because of the limited number of farms who only adopted DC technologies, it was not possible to separately develop a model for this group. Due to the characteristics of technology adoption, in particular the fact that in many cases the technology is not adopted, using the Poisson regression model may not control for the issues of over-dispersion and an excess of zeros (as presented in the histograms in Figure 1 showing distribution of the intensity of technology adoption). To address these issues, we first conducted dispersion tests to test for the existence of over-dispersion in all 3 Poisson regression models. Additionally, we employed zero-inflated models to analyze the sample data and compared the results to those of the Poisson regression models to test for the robustness

\begin{tabular}{|c|c|c|c|}
\hline Item & Labor-saving intensity 1 & Labor-saving intensity 2 & Intensity of both \\
\hline Dependent variable & $\begin{array}{l}\text { Counts of adopting only labor- } \\
\text { saving technologies per farm }\end{array}$ & $\begin{array}{l}\text { Counts of adopting only labor- } \\
\text { saving technologies, as well as both }\end{array}$ & $\begin{array}{l}\text { Counts of adopting labor- } \\
\text { saving and data-capture } \\
\text { technologies }\end{array}$ \\
\hline Independent variable & All $X$ s in Table 2 & $\begin{array}{l}\text { All } X_{\text {S }} \text { in Table } 2 \\
\text { Plus data-capture } \\
\text { Plus data-capture } \times 2013 \\
\text { Plus data-capture } \times 2018\end{array}$ & All $X_{\mathrm{s}}$ in Table 2 \\
\hline
\end{tabular}
of the chosen models.

Table 3. Descriptions of models for intensity of adoption 
Table 4. Regression results of multinominal logit model across 3 parlor technology groupings on New Zealand dairy farms

\begin{tabular}{|c|c|c|c|c|c|c|}
\hline \multirow[b]{2}{*}{ Variable } & \multicolumn{2}{|c|}{ Labor-saving only } & \multicolumn{2}{|c|}{ Data-capture only } & \multicolumn{2}{|c|}{ Both technologies } \\
\hline & Odds & $\mathrm{SE}^{1}$ & Odds & $\mathrm{SE}$ & Odds & $\mathrm{SE}$ \\
\hline Constant & $0.16^{* * *}$ & 0.36 & $0.04^{* * *}$ & 0.15 & $0.003^{* * *}$ & 0.24 \\
\hline Herd size (cows) & 1 & 0.001 & 1 & 0.002 & 1 & 0.001 \\
\hline Stocking rate (cows/ha) & 1.04 & 0.06 & 1 & 0.22 & $1.14^{* *}$ & 0.07 \\
\hline Cows/worker & $1.02 *$ & 0.001 & 1 & 0.005 & $1.03^{*}$ & 0.01 \\
\hline Parlor type ${ }^{2}$ & $4.56^{* *}$ & 0.16 & 0.80 & 0.03 & $5.7^{* * *}$ & 0.28 \\
\hline Parlor age & $0.92^{*}$ & 0.02 & 0.97 & 0.009 & $0.95^{* *}$ & 0.009 \\
\hline Clusters & $1.02^{* *}$ & 0.009 & 0.98 & 0.03 & $1.06^{* * *}$ & 0.01 \\
\hline Owner/operator ${ }^{3}$ & 1.24 & 0.21 & 0.68 & 0.26 & $1.76^{* *}$ & 0.27 \\
\hline Sharemilker ${ }^{4}$ & 1.54 & 0.24 & 1.38 & 0.28 & 1.23 & 0.34 \\
\hline Northland $^{5}$ & $0.62^{*}$ & 0.2 & $0.38 * * *$ & 0.24 & $0.28 * * *$ & 0.21 \\
\hline Bay of Plenty & 1.08 & 0.29 & $0.55^{* * *}$ & 0.08 & 1.18 & 0.36 \\
\hline Taranaki & 1.13 & 0.24 & 1 & 0.43 & 0.66 & 0.32 \\
\hline Lower North Island & 0.96 & 0.23 & $0.6^{* * *}$ & 0.38 & $0.74^{* * *}$ & 0.27 \\
\hline South Island & 0.93 & 0.26 & $1.46^{* *}$ & 0.22 & $1.59^{* *}$ & 0.42 \\
\hline $2013^{6}$ & $1.22^{* * *}$ & 0.17 & 1.68 & 0.42 & $2.65^{*}$ & 0.28 \\
\hline 2018 & $1.21^{* * *}$ & 0.18 & $1.07^{*}$ & 0.12 & $4.78^{* * *}$ & 0.3 \\
\hline $\mathrm{AIC}$ & & & 2,4 & & & \\
\hline Log-likelihood. & & & $-1,1$ & & & \\
\hline McFadden's pseudo $\mathrm{R}^{2}$ & & & & 18 & & \\
\hline \multicolumn{7}{|c|}{$\begin{array}{l}{ }^{1} \text { Standard error and significance levels are associated with the coefficient estimates, }{ }^{*} P<0.1 ;{ }^{* *} P<0.0 \\
{ }_{* * *} P<0.01 \text {. }\end{array}$} \\
\hline \multirow{2}{*}{\multicolumn{7}{|c|}{$\begin{array}{l}{ }^{2} \text { Parlor type base is herringbone. } \\
{ }^{3} \text { The base for business type is other business. }\end{array}$}} \\
\hline & & & & & & \\
\hline \multicolumn{7}{|c|}{$\begin{array}{l}{ }^{4} \text { Sharemilker refers to a person who works another's dairy farm for a share of the profits, sometimes ownir } \\
\text { all or part of the herd. }\end{array}$} \\
\hline${ }^{5}$ Region base is Waikato. & & & & & & \\
\hline${ }^{6}$ Year base is 2008. & & & & & & \\
\hline
\end{tabular}

\section{RESULTS}

\section{Factors that Affect the Amount of Farms Adopting LS and DC Technologies}

Based on Equation 1, the multinominal logit regression results are shown in Table 4, where the estimated odds (also known as relative risk ratios) are presented for ease of interpretation The odds values represent the odds of falling in a specific group (i.e., LS only, DC only, and LS+DC technologies in this paper) over the base group (nonadoption), where the value $>1$ indicates increased occurrence compared with base whereas $<1$ indicates decreased occurrence.

For all 3 adoption decisions, herd size did not affect the likelihood of technology adoption regardless of whether it is LS, DC, or LS+DC. When all other variables in the model were held constant, 2 variables, the dummy for 2018, and the region dummy for Northland were estimated to be statistically significant $(P$ $<0.1$ ) across all 3 technology categories. Farmers in the Northland region were found to be less likely to adopt either one of the technologies individually or both technologies, compared with the Waikato base region. Though statistically significant $(P<0.1)$, the effect of Parlor age and Cows/worker on the adoption of technologies was found to be small. A 1-yr increase in parlor age was estimated to be associated with an 8,3 , and $5 \%$ decrease in the likelihood of adopting LS, DC, and LS+DC technologies, respectively. Time was estimated to positively affect farmers' technology adoption, as the likelihood of technology adoption in 2018 (and 2013 in brackets) increased by 21 (22), 7 (68), and $378 \%$ (165) for LS, DC, and LS+DC technologies, respectively, compared with those in 2008 .

The use of a rotary versus herringbone parlor was estimated to be associated with 360 and $470 \%$ increase in the likelihood of adopting LS technologies and LS+DC, respectively $(P<0.05)$. Although no significant differences were found regarding the adoption of only LS technologies across most surveyed regions (except Northland), significant regional differences $(P<0.05)$ were found for the adoption of DC only and LS+DC technologies. Notably, the likelihood of adopting DC and both LS+DC technologies were found to be 46 and $59 \%$ greater, respectively in the South Island compared with the base region of Waikato.

Compared with the adoption of only one technology category, more variables were found to be statistically significant $(P<0.1)$ for the adoption of both technolo- 
Table 5. Regression results of models examining the intensity of adoption for 3 parlor technology groupings on New Zealand dairy farms

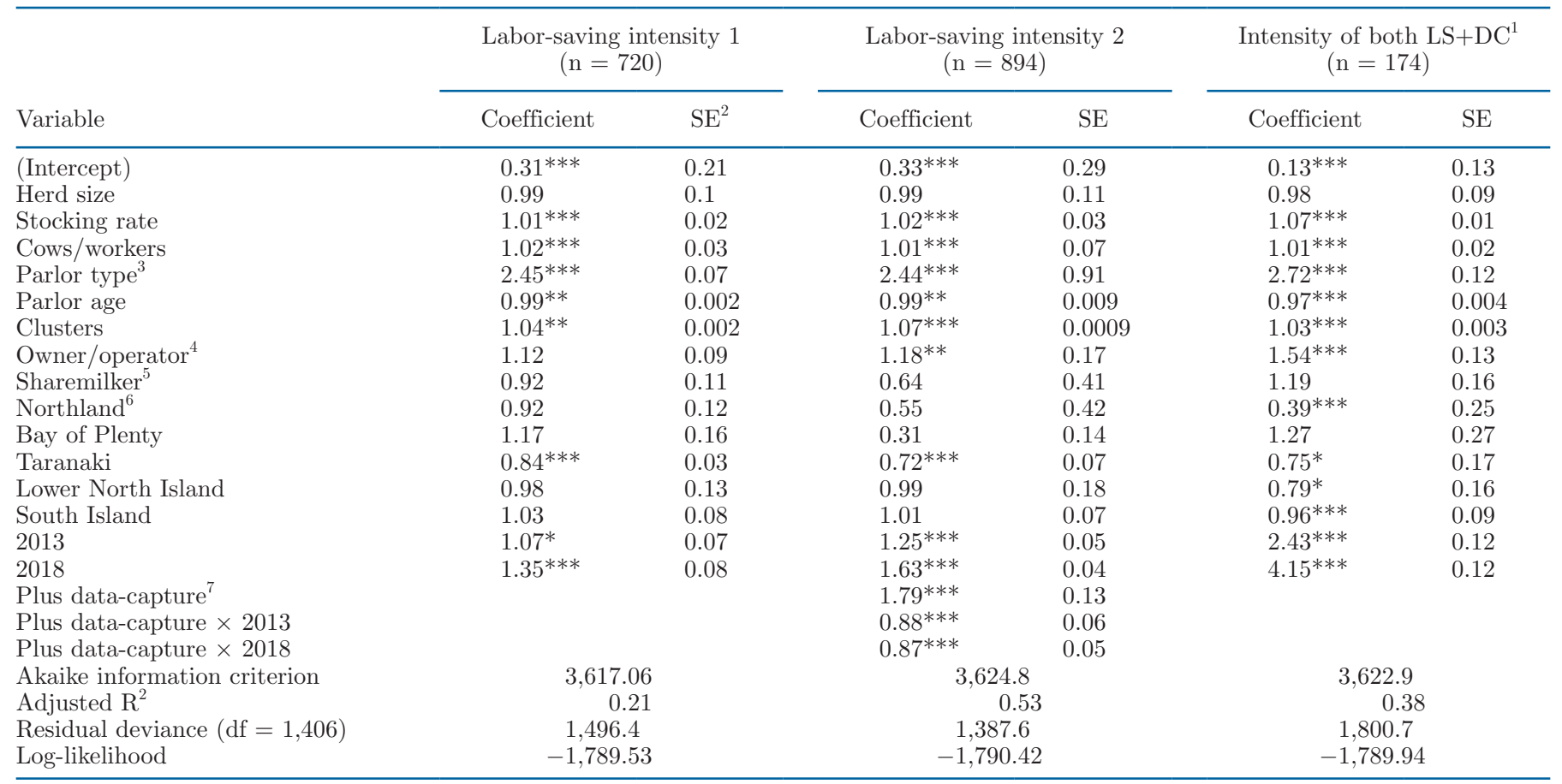

${ }^{1} \mathrm{LS}=$ labor-saving technology; DC = data-capture technology.

${ }^{2}$ Standard error and significance levels are associated with the coefficient estimates, ${ }^{*} P<0.1 ;{ }^{* *} P<0.05 ;{ }^{* * *} P<0.01$.

${ }^{3}$ Parlor type base is herringbone.

${ }^{4}$ The base for business type is other business.

${ }^{5}$ Sharemilker refers to a person who works another's dairy farm for a share of the profits, sometimes owning all or part of the herd.

${ }^{6}$ Region base is Waikato.

${ }^{7}$ Year base is 2008.

gies. Notably, the stocking rate had a positive effect on the likelihood of adoption of both LS+DC technologies, where a $1 \%$ increase in the stocking rate was estimated to increase the likelihood of adoption by $14 \%$. Cows/ worker, Parlor type, Clusters, and being the Owner also increased the odds of adopting LS+DC technologies.

\section{Factors that Affect the Average Per Farm Intensity of LS and DC Technology Adoption}

Three Poisson regression models were used to explore the intensity of adoption, and Table 5 presents the intensity of adoption regression results for all 3 models. Here the results from column 2 to 4 show the extent that different factors affect the expected number of adopted LS technologies per farm, and the last 2 columns present the results of how different factors affect the number of adopted technologies of both types per farm.

Prior to interpreting the estimated results, we first tested for over-dispersion issues in all 3 Poisson regression models. Based on the residual deviance and degree of freedom, shown in Table 5, we calculated the ratio of residual deviance to degree of freedom to test for potential over-dispersion. The ratio for all 3 models was calculated to be close to $1(1.06,0.99$, and 1.27 , respectively), which aligned with recommendations that the ratio should be 1 , indicating the nonexistence of over-dispersion (Aitkin, 1996). Results of the overdispersion tests confirmed this finding, where the $P$ values associated with over-dispersion for all 3 models were found to be greater than 0.05 (Dean and Lawless, 1989; Zeileis et al., 2008). Thus, given over-dispersion was not revealed, we considered it appropriate to use the Poisson regression model.

Based on the model performance indicators shown in Table 5, Akaike information criterion, Adjusted $\mathrm{R}^{2}$ and log-likelihood value, the Labor-saving intensity 2 model performs better than the Labor-saving intensity 1 model regarding goodness of fit. According to the results shown in Table 5 (column 2), for the Labor-saving intensity 1 model, the trend of the estimated results is similar to those in the model for LS only in Table 4, meaning that these factors affected the likelihood and intensity of adopting LS technologies similarly. 
Specifically, having a rotary parlor was associated with an increase in the intensity of LS technology adoption by $145 \%(P<0.05)$. In contrast, an increased parlor age was estimated to decrease the intensity of adoption by only $1 \%$.

For the Labor-saving intensity 2 model, the estimated coefficients for the variables discussed above showed similar tendencies, and the owner-operator variable was also significant $(P<0.05)$, indicating that ownership was positively associated with a greater adoption intensity. In addition, farmers who adopted both LS+DC technologies were found to have a greater LS technology adoption intensity. However, given the estimated interactions between the year dummies and the Plus data-capture variable, this positive effect tended to decrease by $12 \%$ from 2008 to 2013 and $13 \%$ from 2008 to 2018.

The greatest number of significant $(P<0.1)$ variables are found in the LS+DC model. Two significant differences can be observed from this model compared with the other 2 models. First, more regional dummies were estimated to be statistically significant $(P<0.1)$, with South Island having the highest adoption intensity (see Table 5). Second, time was observed to be one of the most significant $(P<0.01)$ factors affecting the adoption intensity of LS+DC technologies, with the number of technologies adopted estimated to be 2.43 (in 2013) and 4.15 (in 2018) times greater than that in 2008.

Sensitivity analyses were conducted to address potential issues associated with the econometric estimation processes. First, the Poisson model may not be able to control for the issue of excess zeros (which could emerge if there is widespread nonadoption of technologies in the sample data). The regressions were therefore repeated using the zero-inflated Poisson model which has been shown to cope with the existence of excess zeros (Zeileis et al., 2008) to assess the extent of the effect on the results. For all 3 levels of adoption models, results of the zero-inflated Poisson models showed only small differences regarding magnitudes and significance levels of the coefficient estimates from those estimated using Poisson regression models. Second, we conducted an outlier test that identified several outliers and therefore we repeated the multinominal logit model and Poisson regression models (all 4 models) with these outliers removed. When the outliers were removed, the magnitude of the coefficient estimates changed slightly. However, the signs and significance levels of the coefficient estimates were consistent with those in Table 4 and Table 5. Results of the sensitivity analyses are included in the Supplemental Tables S2-S4 (https://doi .org/10.3168/jds.2020-18726). Overall, the sensitivity analyses showed estimation results that are similar to, and not statistically different from, our original results, suggesting that our econometric models are robust.

\section{DISCUSSION}

The hypothesis we tested in this study was that over time there would be greater adoption of DC parlor technologies on farms that have also invested in LS technologies compared with farms that have no LS technologies. Surveyed farmers who adopted both LS+DC technologies also tended to have more LS technologies, though the positive effect reduced over time. This indicates that farmers are, in general, installing multiple forms of technologies at the same time. However, adoption of LS technology only or LS+DC technologies both increased over time, suggesting that adoption of DC technologies may not be associated with increased level of LS technologies. We therefore reject the hypothesis. A reason for this result may be that farmers primarily invest in the surveyed technologies when building a new parlor rather than occasional investments, as seen in previous studies (Eastwood et al., 2012). Parlors last for at least 25 years, and their replacement represents a major capital investment for farmers, and therefore they often seek to future-proof their investment by installing technology (e.g., in-parlor milk and mastitis sensors) (Eastwood et al., 2016). As a result, adoption of in-parlor technologies will be more likely to occur in clusters over time on farms. An exception to this would be animal wearables such as automated heat detection, which can often be used without changes to parlor infrastructure.

There were regional and time differences in the adoption of DC technologies. South Island farmers were found to have the highest likelihood of adopting LS+DC technologies; and time effects (both 2013 and 2018) were estimated to be significantly greater on the odds of adopting both technologies than those of adopting only LS technologies. Farmers in the Northland, Bay of Plenty, Lower North Island regions in the survey exhibited lower likelihood of installing of DC tools, whereas South Island farmers showed greater likelihood of adoption, compared with those in the Waikato region. The 3 North Island regions (Northland, Bay of Plenty and Lower North Island) have farms and herd sizes that are generally lower than the national average (DairyNZ, 2019), and the age of parlors is $24.1 \mathrm{yr}$ in relation to the average (21.8) in this current survey; comparatively, the South Island dairy farms are larger and have newer parlors (14.7 yr on average). The age of parlors in these different regions may be a major influence on the uptake of in-parlor DC technologies, as these technologies are difficult to retrofit into existing parlors. Also, as some of the DC technologies only en- 
tered the market 10 to $15 \mathrm{yr}$ ago, therefore the majority of parlors were built before the technology existed. Farm size may also have been linked to the regional differences, with farmers on the smaller farms in the North Island regions struggling to justify technology investments due to some technology costs being fixed (i.e., greater per-cow investment cost), less issues with recruiting and managing large farm labor teams, and a greater ability to manage their herds via traditional approaches. However, herd size did not have a significant effect on adoption, suggesting that farm size is less of a factor than farm systems aspects such as land values, productivity potential and profitability.

In the current study, surveyed farms with higher stocking rates had a greater LS adoption intensity, as well as adoption of both LS+DC. Also, on farms with rotaries or with larger parlors with more milking clusters, there was a greater intensity of LS technology adoption. The trend of greater adoption of LS technologies on larger dairy farms with rotary parlors is supported by a previous study by Gargiulo et al. (2018). In our study however, parlor age had little effect on adoption intensity, this may be due to slow updating of sheds and the installation of technology being linked to shed replacement, as suggested by Eastwood et al. (2016). Farms run by owner-operators had a greater intensity of LS only or LS+DC technologies. This may be because owner-operators are more linked to the performance of the milking parlor, compared with decision makers in corporate farming businesses, and therefore are more likely to factor in lifestyle benefits associated with such technologies. Finally, the results indicate that farms with LS+DC technologies also had a greater intensity of LS technology adoption, suggesting a link between the value proposition for different technologies on particular farm types. Survey participants were not directly asked about their perceptions of the value associated with individual technologies, however, in study of similar technologies, farmers indicated a range of reasons for adopting technology including to save time, make milking easier, and to more easily attract staff (Eastwood et al., 2016). The value proposition that farmers place on technologies is influenced by the farm context, for example goals, existing infrastructure, risk profile and advisory support networks (Kuehne et al., 2017). Further research focused on these aspects related to in-parlor technology adoption is warranted to expand understanding of adoption trends.

The current study provides insights for the adoption of multiple technologies in different parlor types and farming regions. Compared with the Waikato region, the relatively low adoption intensity of both technology groups (LS+DC) found in the South Island region, where there are newer parlors and larger farms, is a surprising result. That is, greater likelihood of adopting one of the 8 surveyed technologies was not necessarily associated with a farmer adopting one or more of the other 7 technologies. This may indicate an area where farmers are focused on automating tasks in their large parlors, for example just investing in automated cup removers, but relying on staff to carry out tasks that DC devices would otherwise be used to augment. Previous studies across NZ dairy regions (Eastwood et al. 2015, 2016) have not uncovered this trend and this presents an area for future investigation. These data may indicate occurrence of 2 trajectories to technology investment on farms, where larger farms are able to take advantage of technology opportunities, but smaller farms are constrained by factors such as lack of economies of scale, limited capital to invest, and inability to retrofit into aging parlor infrastructure. Such limitations have implications for the adoption of technology on smaller farms (Ayre et al., 2019; Klerkx et al., 2019).

The 3 surveys in this study provide unique insights on time trends in technology adoption from 2008 to 2018. Over this period there was no increase in the proportion of NZ dairy farms with only LS technologies, but the number of LS technologies per farm increased from 1.67 (2008) different LS technologies per farm to 2.16 (2018). The greatest change was in data-capture technologies, with a large increase $(378 \%)$ in the LS+DC grouping over the decade, however, this may be strongly influenced by rise to 82 farms with LS+DC (2018) from a low initial base (28 farms) in 2008 (Table 2 ). Within the DC grouping, the use of automated heat detection showed the highest increase over time, indicating that this became a more attractive option for farmers due to changes in technology design and cost, and potentially also due to ease in adding this technology to existing parlor systems, rather than needing an extensive retrofit.

These insights have implications for other dairy industries globally. The NZ dairy industry has changed considerably in the past 20 years in terms of farm systems, herd sizes, and milking infrastructure investment. Most NZ dairy farms are pasture-based and stocking rates average 2.9 cows/ha with cows producing an average of 4,200 L/cow; however, there has been an increase in the levels of supplementary feed used including maize and pasture silage and palm kernel expeller over the past decade (Ledgard et al., 2020). Between 2000 and 2015 the national dairy herd grew by $3 \%$ per year. Over the same period, there was an $18 \%$ decline in the number of herds between 2000 and 2007, which was followed by a period of farm (arable and sheep/ beef) conversions to dairy until 2015 (typically large herds in the South Island). The net effect has been an increase in average herd size from 251 in 2000 to 
419 in 2015 (and 435 by 2019). These changes have differed by region, for example between 2000 and 2019 the North Island average herd size grew from 232 to 354 cows, whereas the South Island grew from 354 to 639 cows. The South Island regions (for example Canterbury and Southland) have higher average stocking rates, per-cow milk production, and use of irrigation compared with North Island regions (Ledgard et al., 2020). The larger farm sizes, and new farm conversions, in the South Island (Canterbury and Southland) mean that the parlor infrastructure is generally younger than seen in the North Island. Trends of declining numbers of herds, and increasing herd sizes have been reported in other countries, such as the United States (Britt et al., 2018) and Ireland since the removal of milk quotas in 2015 (Kelly et al., 2020). Continuation of these trends will require management changes for larger and more complex farming systems with increased need for staff, potentially influencing future demand for automation and sensor technology on farms. Results from the present study, for example greater intensity (145\%) in rotary parlors and regional differences, could be used to predict adoption trends in dairy industries such as Ireland, allowing for forward planning by industry research and development organization and technology suppliers.

Greater use of on-farm technology is being seen as a method to increase both productivity and sustainability of farms globally (Shepherd et al., 2018). The benefits of LS technologies are primarily associated with labor productivity, whereas farm sustainability improvements require better data and decision-making. The results of our study highlight that, over time, automation technologies for labor-saving have been adopted more intensively than sensor technologies for capturing data. On-farm technology adoption processes typically include a multitude of factors such as return on investment, risk orientation, technology awareness, advisory support, and technology performance and system integration (Rose et al., 2016; Kuehne et al., 2017). Technology adoption trends in the current study suggest that technology uptake is impaired by the difficulty of retrofitting technologies into older milking parlors. Farmers are therefore incentivized to install parlor-based technologies at the time of a major parlor upgrade because it's easier and cheaper than doing it later, and this limits technology stacking where farmers iteratively invest in technologies (Eastwood et al., 2016). The fixed costs associated with hardware such as automated drafting leads to greater per-cow costs for smaller farms, compared with wearable technologies or subscription business models that charge a per-cow fee. Enabling small and large farmers to make more strategic technology adoption decisions requires technology developers, and industry/government organizations, to focus on technology design, and pricing models, to facilitate stacking. This means technologies will need to have greater interoperability, easier data transfer, and integrate with farm management software (Bahlo et al., 2019), and also be able to stand alone from the existing farm infrastructure and technologies.

Limitations of this study are mainly based around the lack of farm identifiers in the surveying stage. Participants were assured of anonymity and farm identifiers were not collected; therefore, the analysis does not represent the same 500 farms over time, rather a representative snapshot of the NZ dairy sector over time at a national level. This precluded the tracing of technology adoption at an individual farm level. Additionally, due to the need to limit the length of the phone survey to around 15 min, only selected farm/farmer characteristics were collected (sex, age, ownership structure, herd size, farm location, and farm systems information). This limited further analysis related to innovation drivers such as farmer education, access to information sources and advisory support. This paper reports a novel study of longitudinal adoption trends in parlor technologies, using an econometric modeling approach. The models developed in the current paper could be used and further tested in future studies to conduct predictions, particularly where more data on aspects such as farm profitability and characteristics of farm decision makers is collected.

\section{CONCLUSIONS}

This study provides novel insights into trends in adoption of in-parlor technology over time. Technology adoption increased over time in the surveyed population, and the largest increases were seen for labor-saving technologies. Although there were small increases in the proportion of DC technologies on farms over time, these technologies were adopted more strongly where there was also a high proportion of LS technologies. This indicates farmers are less likely to invest in DC technologies alone, or that there are types of farms (for example certain management styles) where LS and DC are a more viable combination. Further research is required into the factors influencing adoption or nonadoption of data-capture technologies. Differences in adoption also related to factors such as the type of parlor and region. Greater adoption in rotary parlors makes sense in the NZ context where these parlors are associated with newer infrastructure, larger farms, and milking practices that align well with technologies such as automated drafting and automated cup removers. The regional differences in adoption, may also be related to farm type and age of milking infrastructure, but the drivers may 
be more complex than this. Regional differences warrant further research, for example, to understand the wider effect of farm and farmer characteristics such as farmer career stage, support networks, farm ownership structure, farm debt levels, and innovation mindset on precision technology investment. The results highlight the importance of understanding spatial and temporal farm characteristics when considering future effect and adoption of precision dairy technologies.

\section{ACKNOWLEDGMENTS}

The authors thank the farmers who participated in the phone surveys for their time and insight. This study was funded by the Dairy Farmers of New Zealand through DairyNZ Inc. (Hamilton, New Zealand), contract WEN1802 (Systems for People). The authors have not stated any conflicts of interest.

\section{REFERENCES}

Aitkin, M. 1996. A general maximum likelihood analysis of overdispersion in generalized linear models. Stat. Comput. 6:251-262. https: //doi.org/10.1007/BF00140869.

Ayre, M., V. Mc Collum, W. Waters, P. Samson, A. Curro, R. Nettle, J.-A. Paschen, B. King, and N. Reichelt. 2019. Supporting and practising digital innovation with advisers in smart farming. NJAS Wag. J. Life Sci. 90-91:100302.

Bahlo, C., P. Dahlhaus, H. Thompson, and M. Trotter. 2019. The role of interoperable data standards in precision livestock farming in extensive livestock systems: A review. Comp. Electron. Agric. 156:459-466. https://doi.org/10.1016/j.compag.2018.12.007.

Barnes, A. P., I. Soto, V. Eory, B. Beck, A. Balafoutis, B. Sánchez, J. Vangeyte, S. Fountas, T. van der Wal, and M. Gómez-Barbero. 2019. Exploring the adoption of precision agricultural technologies: A cross regional study of EU farmers. Land Use Policy 80:163-174. https://doi.org/10.1016/j.landusepol.2018.10.004.

Borchers, M. R., and J. M. Bewley. 2015. An assessment of producer precision dairy farming technology use, prepurchase considerations, and usefulness. J. Dairy Sci. 98:4198-4205. https://doi .org/10.3168/jds.2014-8963.

Britt, J. H., R. A. Cushman, C. D. Dechow, H. Dobson, P. Humblot, M. F. Hutjens, G. A. Jones, P. S. Ruegg, I. M. Sheldon, and J. S. Stevenson. 2018. Invited review: Learning from the future-A vision for dairy farms and cows in 2067. J. Dairy Sci. 101:3722-3741. https://doi.org/10.3168/jds.2017-14025.

Byerlee, D., and E. H. de Polanco. 1986. Farmers' stepwise adoption of technological packages: Evidence from the Mexican altiplano. Am. J. Agric. Econ. 68:519-527. https://doi.org/10.2307/1241537.

DairyNZ. 2019. New Zealand Dairy Statistics 2018-19. Livestock Improvement Corporation, Hamilton, New Zealand.

Dean, C., and J. F. Lawless. 1989. Tests for detecting overdispersion in poisson regression models. J. Am. Stat. Assoc. 84:467-472. https:/ /doi.org/10.1080/01621459.1989.10478792.

Dela Rue, B. T., C. R. Eastwood, J. P. Edwards, and S. Cuthbert. 2020. New Zealand dairy farmers preference investments in automation technology over decision-support technology. Anim. Prod. Sci. 60:133-137. https://doi.org/10.1071/AN18566.

Deming, J., D. Gleeson, T. O'Dwyer, J. Kinsella, and B. O'Brien. 2018. Measuring labor input on pasture-based dairy farms using a smartphone. J. Dairy Sci. 101:9527-9543. https://doi.org/10 $.3168 /$ jds.2017-14288

Deming, J., J. Kinsella, B. O'Brien, and L. Shalloo. 2019. An examination of the effects of labor efficiency on the profitability of grass- based, seasonal-calving dairy farms. J. Dairy Sci. 102:8431-8440. https://doi.org/10.3168/jds.2018-15299.

Dolecheck, K. A., G. Heersche Jr., and J. M. Bewley. 2016. Retention payoff-based cost per day open regression equations: Application in a user-friendly decision support tool for investment analysis of automated estrus detection technologies. J. Dairy Sci. 99:1018210193. https://doi.org/10.3168/jds.2015-10364.

Eastwood, C. R., D. F. Chapman, and M. S. Paine. 2012. Networks of practice for co-construction of agricultural decision support systems: Case studies of precision dairy farms in Australia. Agric. Syst. 108:10-18. https://doi.org/10.1016/j.agsy.2011.12.005.

Eastwood, C. R., J. Greer, D. Schmidt, J. Muir, and K. Sargeant. 2020. Identifying current challenges and research priorities to guide the design of more attractive dairy-farm workplaces in New Zealand. Anim. Prod. Sci. 60:84-88. https://doi.org/10.1071/AN18568.

Eastwood, C. R., J. G. Jago, J. P. Edwards, and J. K. Burke. 2016. Getting the most out of advanced farm management technologies: Roles of technology suppliers and dairy industry organisations in supporting precision dairy farmers. Anim. Prod. Sci. 56:1752-1760. https://doi.org/10.1071/AN141015.

Edwards, J. P., B. T. Dela Rue, and J. G. Jago. 2015. Evaluating rates of technology adoption and milking practices on New Zealand dairy farms. Anim. Prod. Sci. 55:702-709. https://doi.org/10 .1071/AN14065.

Edwards, J. P., B. Kuhn-Sherlock, B. T. Dela Rue, and C. R. Eastwood. 2020. Short communication: Technologies and milking practices that reduce hours of work and increase flexibility through milking efficiency in pasture-based dairy farm systems. J. Dairy Sci. 103:7172-7179. https://doi.org/10.3168/jds.2019-17941.

Gargiulo, J. I., C. R. Eastwood, S. C. Garcia, and N. A. Lyons. 2018. Dairy farmers with larger herd sizes adopt more precision dairy technologies. J. Dairy Sci. 101:5466-5473. https://doi.org/10 .3168/jds.2017-13324.

Higgins, V., M. Bryant, A. Howell, and J. Battersby. 2017. Ordering adoption: Materiality, knowledge and farmer engagement with precision agriculture technologies. J. Rural Stud. 55:193-202. https:/ /doi.org/10.1016/j.jrurstud.2017.08.011.

Kelly, P., L. Shalloo, M. Wallace, and P. Dillon. 2020. The Irish dairy industry - Recent history and strategy, current state and future challenges. Int. J. Dairy Technol. 73:309-323. https://doi.org/10 $.1111 / 1471-0307.12682$.

Klerkx, L., E. Jakku, and P. Labarthe. 2019. A review of social science on digital agriculture, smart farming and agriculture 4.0: New contributions and a future research agenda. NJAS Wag. J. Life Sci. 90-91:100315. https://doi.org/10.1016/j.njas.2019.100315.

Kuehne, G., R. Llewellyn, D. J. Pannell, R. Wilkinson, P. Dolling, J. Ouzman, and M. Ewing. 2017. Predicting farmer uptake of new agricultural practices: A tool for research, extension and policy. Agric. Syst. 156:115-125. https://doi.org/10.1016/j.agsy.2017.06 .007 .

Ledgard, S. F., S. J. Falconer, R. Abercrombie, G. Philip, and J. P. Hill. 2020. Temporal, spatial, and management variability in the carbon footprint of New Zealand milk. J. Dairy Sci. 103:10311046. https://doi.org/10.3168/jds.2019-17182.

Rose, D. C., W. J. Sutherland, C. Parker, M. Lobley, M. Winter, C. Morris, S. Twining, C. Ffoulkes, T. Amano, and L. V. Dicks. 2016. Decision support tools for agriculture: Towards effective design and delivery. Agric. Syst. 149:165-174. https://doi.org/10.1016/j .agsy.2016.09.009.

Rutten, C. J., W. Steeneveld, A. G. J. M. Oude Lansink, and H. Hogeveen. 2018. Delaying investments in sensor technology: The rationality of dairy farmers' investment decisions illustrated within the framework of real options theory. J. Dairy Sci. 101:7650-7660. https://doi.org/10.3168/jds.2017-13358.

Rutten, C. J., A. G. J. Velthuis, W. Steeneveld, and H. Hogeveen. 2013. Invited review: Sensors to support health management on dairy farms. J. Dairy Sci. 96:1928-1952. https://doi.org/10.3168/ jds.2012-6107.

Shadbolt, N., D. Apparao, S. Hunter, K. Bicknell, and A. Dooley. 2017. Scenario analysis to determine possible, plausible futures for 
the New Zealand dairy industry. N. Z. J. Agric. Res. 60:349-361. https://doi.org/10.1080/00288233.2017.1351377.

Shepherd, M., J. A. Turner, B. Small, and D. Wheeler. 2018. Priorities for science to overcome hurdles thwarting the full promise of the 'digital agriculture' revolution. J. Sci. Food Agric. Online only. https://doi.org/10.1002/jsfa.9346.

Smith, M. J. 2020. Getting value from artificial intelligence in agriculture. Anim. Prod. Sci. 60:46-54. https://doi.org/10.1071/ AN18522.

Thomas, E. B., K. A. Dolecheck, T. B. Mark, C. R. Eastwood, B. T. Dela Rue, and J. M. Bewley. 2019. A decision-support tool for investment analysis of automated oestrus detection technologies in a seasonal dairy production system. Anim. Prod. Sci. 59:2280-2287. https://doi.org/10.1071/AN17730.

van den Pol-van Dasselaar, A., D. Hennessy, and J. Isselstein. 2020. Grazing of dairy cows in Europe - An in-depth analysis based on the perception of grassland experts. Sustainability 12:1098. https: //doi.org/10.3390/su12031098.
Wolfert, S., L. Ge, C. Verdouw, and M.-J. Bogaardt. 2017. Big data in smart farming - A review. Agric. Syst. 153:69-80. https://doi.org/ 10.1016/j.agsy.2017.01.023.

Zeileis, A., C. Kleiber, and S. Jackman. 2008. Regression models for count data in R. J. Stat. Soft. 27:25.

\section{ORCIDS}

W. Yang (® https://orcid.org/0000-0003-1046-2703

J. P. Edwards () https://orcid.org/0000-0003-4220-7408

C. R. Eastwood ๑ https://orcid.org/0000-0002-1072-5078

B. T. Dela Rue $\odot$ https://orcid.org/0000-0001-7739-603X

A. Renwick (ㅇ https://orcid.org/0000-0002-4756-5709 